\title{
3 Research Square

\section{Do the Successful Revision Surgery for Humeral Nonunion Solve all the Effects on Health-Related Quality of life? A Retrospective Cohort Study}

\section{Zhimeng Wang}

Xi'an Hong Hui Hospital

Yao Lu

Xi'an Hong Hui Hospital

Liang Sun

Xi'an Hong Hui Hospital

Leilei Song

Qinghai Medical College: Qinghai University Medical College

Teng Ma

Xi'an Hong Hui Hospital

Qiang Wang

Xi'an Hong Hui Hospital

Kun Zhang ( $\square$ hhzhangkun@163.com )

Xi'an Jiaotong University College of Medicine

Zhong Li

Xi'an Hong Hui Hospital

Research article

Keywords: humerus, nonunion, quality of life, revision surgery, SF-12

Posted Date: February 16th, 2021

DOI: https://doi.org/10.21203/rs.3.rs-241602/v1

License: (1) (1) This work is licensed under a Creative Commons Attribution 4.0 International License.

Read Full License 


\section{Abstract}

Background To evaluate the effects of successful revision operation on health quality of life(QoL) and functional outcome in humeral nonunion patients.

Methods This retrospective study included 62 patients with humeral nonunion from Northwest China, who were admitted to the Department of Trauma Surgery, Honghui Hospital between March 2013 and September 2019. The following data were retrospectively evaluated: demographic data, clinical data, imaging findings, and treatment methods. The QoL assessment indicators for humeral nonunion patients included the SF-12 mental component summary(MCS) and physical component summary(PCS),brief pain inventory-severity(BPI-S) and brief pain inventory-interference (BPI-I). The mayo elbow performance score(MEPS) was used to assess the elbow function of the patients.

Results Successful revision surgery significantly improved the patient's PCS,MCS,BPI-S and BPI-I scores $(p<0.001)$. According to the MEPS criteria, the excellent and good rates were $95.16 \%$ in this study. The impact of humeral nonunion on mental health was comparable with the reported impact of stroke and

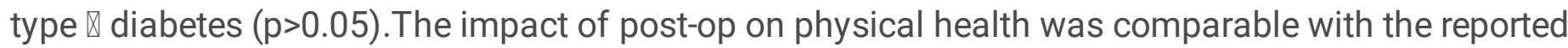
impact of COPD, silicosis, hypertension, barrentt's esophagus and lower urinary tract symptoms $(p>0.05)$.

Conclusion Humeral nonunion is a devastating chronic medical condition that negatively affects both physical and mental health as well as quality of life. Although the effects of pain in the body can be completely relieved by treatment, the entire medical process may cause everlasting psychological trauma to the patient.

\section{Background}

Humeral fractures are common, and both conservative treatment and surgery can achieve good prognosis ${ }^{1}$. The humeral nonunion rate was up to $1 \% \sim 13 \%$ among all fracture complications ${ }^{2,3}$. Nonunion not only causes serious functional and financial burdens but also poses several problems for patients' mental health and social stability ${ }^{4-6}$. However, the treatment of humeral nonunion is more often challenging, requiring one or more surgical interventions, which have high complication rates such as radial nerve palsy or joint stiffness ${ }^{7}$.

Due to the unique problems of humeral nonunion, several treatment options are detailed in the literature ${ }^{7-}$

9 . The short and midterm surgical outcomes have been evaluated in most cases in terms of bone union, range of motion(ROM), infection rate and loss of strength. Nowadays, in China's medical environment, surgical results and interests are often given first priority, ignoring the patient's long-term pain and psychological trauma. Compared with other nonunion complications, pain has an important impact on the health status and quality of life(QoL) of patients, with chronic orthopedic injuries such as nonunion affecting psychosocial regulation and daily functions ${ }^{10}$. 
There are few reports on the final follow-up results of QoL and functional outcomes of patients with humeral nonunion after repair operation. In addition, the general education level in Northwest China is low and cognitive level is not uniform, so the SF-12 scale has the advantages of easier understanding and acceptance, which is more suitable for patients with humeral nonunion ${ }^{11}$. The purpose of this study was to evaluate the health-related QoL and functional outcomes in humeral nonunion patients.

\section{Patients And Methods}

\section{Patients}

A total of 62 patients who underwent revision surgery for humeral nonunion between March 2013 and September 2019 at the Department of Trauma Surgery, Honghui Hospital were included in this retrospective cohort study.

\section{Study Site}

In China, hospitals are categorized in accordance with the medical level into three grades (third-grade is the best), and each grade is divided into three classes from good to bad: A, B, C. As a tertiary-A trauma center, Honghui Hospital is a designated trauma referral center in Northwest China.

\section{Inclusion criteria of humeral nonunion}

(i)Patients with humeral nonunion from Northwest China. (ii)Older than 18 years and with certain cognitive abilities. (iii) We defined "nonunion" according to the US FDA (food and drug administration,FDA) criteria, where a fracture that is at least 9 months old has not shown any signs of healing for three consecutive monthsis ${ }^{12}$.(iv) Patients who agreed to participate in this study and had complete follow-up data. (v) "Fresh nonunion" meant that patients had not undergone prior revision surgery.

\section{Exclusion criteria of humeral nonunion}

(i)The original fracture type was pathological. (ii) Patients with physical conditions who could not tolerate surgery. (iii) Patients who had recently used glucocorticoids and immunosuppressive agents. (iv) Died halfway or quit halfway during the study.

\section{Fracture Healing Criteria}

No local pain after holding heavy objects, no tenderness in the fracture space, imaging showed that at least three sides of the humerus had continuous osteophytes, no internal fixation failure ${ }^{13-15}$. 


\section{Ethics Statement}

This study was approved by the Ethics Committee of Honghui Hospital.

\section{Research methods}

All patients with humeral nonunion who were treated at our institution over one year period; the treatment had been completed and was retrospectively evaluated. The research team included three post-graduates, two attending physicians, and one chief physician, who were responsible for data collection, follow-up and revision surgery treatment. Thorough cleaning of fracture ends, satisfactory reduction, firm internal fixation and sufficient autogenous bone grafting was the treatment principle for humeral nonunion ${ }^{16}$. Follow-up methods included e-mail, telephone and outpatient visits, and the follow-up information was collected every three months.

The following patients' characteristics were recorded: age, gender, smoking, alcohol abuse, body mass index(BMI), etiology, and comorbidities. The following clinical symptoms and performance were recorded: fracture type, primary therapeutic scheme, primary nonunion time, pathological type of nonunion, and autogenous bone grafting. The mayo elbow performance score(MEPS) was used to assess the elbow function of the patient in terms of range of activity, stability, pain and daily living ability ${ }^{17}$. Health-related QoL was evaluated using the short form-12 health survey(SF-12) ${ }^{18}$. The SF-12 scale has 12 entries and evaluates eight dimensions of health-related QoL: general health(GH), physiological function(PF),role physiological(RP),body pain(BP), vitality(VT), social function(SF), role emotional(RE) and mental health(MH). The physical component summary(PCS) consists of GH, PF, RP, and BP. The mental component summary(MCS) consists of SF, RE, MH and VT. The brief pain inventory(BPI) is a widely used basic questionnaire assessing pain interference, which includes 11 entries and two dimensions (BPI-S and $\mathrm{BPI}-\mathrm{I})^{19,20}$.

In addition, we compared the SF-12 scores between Chinese humeral nonunion patients and a series of acute and chronic diseases ${ }^{21-37}$, which allowed the doctors and patients to easily understand the extent to which humeral nonunion affected QoL.

\section{Statistical methods}

Continuous variables are expressed as Mean \pm SD and categorical variables as percentages (\%). For parametric variables, Student's t-test was used to compare between the groups. Unpaired T test was used to compare SF-12 scores of humeral nonunion patients with chronic disease patients. Significance was set at $p<0.05$. All statistical analysis was performed using graphpadism 8.0.

\section{Results}

(i) Between March 2013 and September 2019, a total of 62 patients with humeral nonunion underwent revision surgery at our The patients were aged $20-73$ years (mean $42.3 \pm 4.17$ years). There were 43 
males and 19 females; of which 15 were smokers and seven were alcohol The average BMI was $25.7 \pm$ $2.18 \mathrm{~kg} / \mathrm{m}^{2}$. There were 36 cases of handness and 26 cases of non-handness; physical labor was highrisk group (37 cases, 59.68\%). Fall was the commonest cause of injury (43 cases, $69.4 \%$ ); hypertension was a common complication (11 cases, $17.7 \%$ ); closed fracture was the commonest fracture type (55 cases, $88.7 \%$ ). There were two cases of proximal nonunion, 51 cases of shaft nonunion, and seven cases of distal humerus. The average time from initial injury to nonunion was $7.4 \pm 1.07$ months (range, 616 months). There were 19 cases of atrophy, 14 cases of malnutrition, and 29 cases of hypertrophy. Local pain was the major complaint of most patients (39 cases, 62.90\%) (Table 1).

(ii) Change of SF-12 and BPI scores: At the final follow-up, the SF-12 PCS, SF-12 MCS, BPI-S and BPI-I scores were $43.6 \pm 8.1,34.7 \pm 4.4,4.4 \pm 2.1$, and $4.1 \pm 1.9$, respectively, which were significantly improved as compared to preoperative scores ( $<<0.001$,Table 2$)$. Although the final MCS score had also improved, the magnitude of the change was minimal. 
Table 1

Patients' characteristics

\begin{tabular}{|c|c|}
\hline Patients' characteristics & value(\%) \\
\hline Age $($ mean $\pm S D, y)$ & $42.29 \pm 4.17$ \\
\hline \multicolumn{2}{|l|}{ Gender } \\
\hline male & $43(69.35 \%)$ \\
\hline female & $19(30.65 \%)$ \\
\hline \multicolumn{2}{|l|}{ Smoking } \\
\hline yes & $15(24.19 \%)$ \\
\hline no & $47(75.81 \%)$ \\
\hline \multicolumn{2}{|l|}{ Alcohol abuse } \\
\hline yes & $7(11.29 \%)$ \\
\hline no & $55(88.71 \%)$ \\
\hline $\mathrm{BMI}\left(\operatorname{mean} \pm \mathrm{SD}, \mathrm{kg} / \mathrm{m}^{2}\right)$ & $25.71 \pm 2.18$ \\
\hline \multicolumn{2}{|l|}{ Handness Inventory } \\
\hline handness & $36(58.06 \%)$ \\
\hline non-handness & $26(41.94 \%)$ \\
\hline \multicolumn{2}{|l|}{ Occupation } \\
\hline physical labor & $37(59.68 \%)$ \\
\hline mental worker & $19(30.65 \%)$ \\
\hline retirees & $6(9.67 \%)$ \\
\hline \multicolumn{2}{|l|}{ Etiology } \\
\hline low fall & $24(38.71 \%)$ \\
\hline high fall & $19(30.65 \%)$ \\
\hline MCVs & $8(12.90 \%)$ \\
\hline fall objects & $7(11.29 \%)$ \\
\hline sport & $4(6.45 \%)$ \\
\hline
\end{tabular}

Other^ included prostatitis, osteoporosis, hepatitis. Abbreviations: BMI, body mass index; MVCs, motor vehicle collisions. 


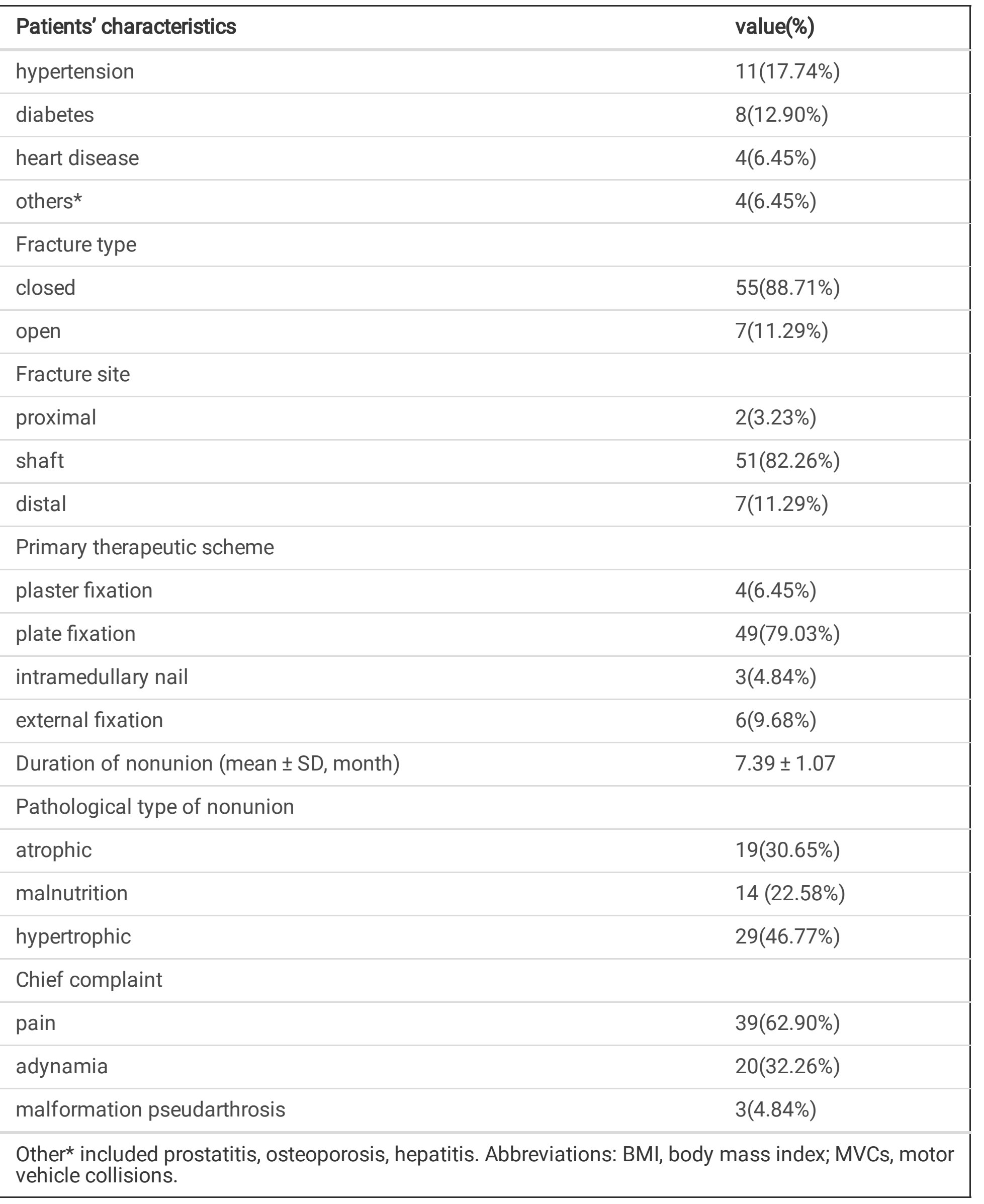


Table 2

Comparison of SF-12 PCS, SF-12 MCS, BPI-S and BPI-I scores between pre-op and post-op in humeral nonunion patients

\begin{tabular}{|lllll|}
\hline Variable & Pre-op & Post-op & t value & $p$ value \\
\hline SF-12 PCS (score, mean \pm sd) & $24.3 \pm 5.2$ & $43.6 \pm 8.1$ & 15.79 & $<0.001$ \\
\hline SF-12 MCS (score, mean \pm sd) & $26.3 \pm 3.8$ & $34.7 \pm 4.4$ & 11.38 & $<0.001$ \\
\hline BPI-S (score, mean \pm sd) & $6.5 \pm 1.9$ & $4.4 \pm 2.1$ & 5.839 & $<0.001$ \\
\hline BPI-I (score, mean \pm sd) & $6.7 \pm 2.5$ & $4.1 \pm 1.9$ & 6.520 & $<0.001$ \\
\hline
\end{tabular}

"Post-op" means that the fracture ends were healed smoothly.

(iv) Influence of Humeral Nonunion on Physical Health

The preoperative SF-12 PCS score of humeral nonunion is the lowest of all included in the literature, and

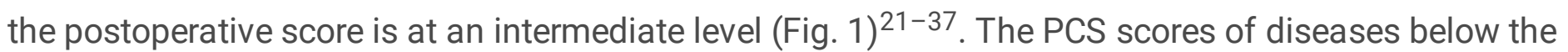
dashed line were significantly better than pro-op, and the differences were all statistically significant $(p<$ 0.05). The mean impact of post-op on physical health was comparable with the reported impact of COPD,silicosis, hypertension,barrentt's esophagus and lower urinary tract symptoms. The post-op impact was significantly worse than that of thyroid cancer $(p<0.001)$, osteoporosis $(p<0.001)$, chronic alcoholism $(p<0.001)$, low-income group $(p<0.001)$, breast cancer $(p<0.001)$, pregnant woman $(p<0.001)$, prostate cancer $(p=0.005)$, as well as coronary heart disease $(p=0.0361)$. Moreover, the mean pro-op and post-op PCS score was significantly below the theoretical Chinese population standard level.

(v) Influence of Humeral Nonunion on Mental Health

Humeral nonunion Patients have a low MCS score in all the literature reviewed (Fig. 2) ${ }^{21-37}$. Revision surgery does not significantly improve the mental health scores of patients with humeral nonunion, although the difference in scores before and after revision surgery were statistically significant $(\mathrm{p}<$ 0.001). The mean impact of humeral nonunion on mental health was comparable with the reported

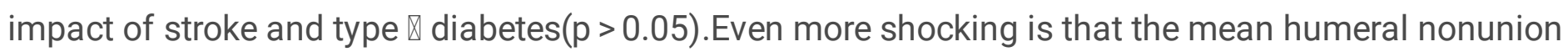
MCS scores of pro-op and post-op were only superior to those of severe depression (all $p<0.001$ ).

\section{Discussion}

Nonunion is a chronic disease that can cause severe pain and disability in the limbs, which has a devastating effect on health-related QoL. To the best of our knowledge, this is the first study in which health-related QoL measures have been reported for patients with humeral nonunion.

Many clinical studies have shown that long bone nonunion causes severe pain and disability, which has major negative impact on patients' daily life and $\mathrm{QoL}^{4,5,10}$. Femoral nonunion and tibial nonunion have a significantly higher attenuation effect on physical and psychological health than other orthopedic or non- 
orthopedic diseases, such as patellofemoral instability, shoulder instability, meniscus tear, ankle osteoarthritis, knee cartilage injury, rotator cuff tear, congestive heart failure, anterior cruciate ligament rupture, type II diabetes, myocardial infarction, depression and hypertension ${ }^{5,38}$. Given that lower limbs long bone nonunion caused such a substantial burden, we investigated whether upper limb nonunion such as humeral nonunion causes similar low scores and has a profound negative effect on a patient's health-related QoL.

Currently, the evaluation indexes of health-related QoL mainly include SF-36 scale, SF-12 scale, BPI scale, etc. The SF-12 is a brief version of SF-36 QoL scale, which is widely used in different countries and has a high correlation with the original health questionnaire SF-36. Lee et al. ${ }^{18}$ verified that the Chinese version of SF-12 scale was also suitable for the Chinese population, which has the advantages of simple entry, concision, easy to understand and less operation time, therefore, it is often used to evaluate the QoL. The BPI scale was designed by Cleeland and Ryan ${ }^{20}$. It has been widely used as a clinical assessment tool and translated into many languages. The Chinese version of BPI had been widely used in the assessment of acute and chronic pain, and cancer pain ${ }^{39}$. The Mayo elbow performance score (MEPS) was used to assess the elbow function of the patients in terms of range of activity, stability, pain and daily living ability.

The results indicated that after receiving humeral nonunion repair surgery, the patients' PCS, MCS, BPI-S and BPI-I scores improved, with most significant changes in BPI-S and BPI-I. The higher score on the SF12 PCS post-operation reflects good physical health, indicates no limitations in self-care and physical activities and satisfactory self-sensation in daily life. Notably, the impact on physical health was comparable with the reported impact of hypertension, even though the fracture was healing. The low score on the SF-12 MCS after revision operation reflects general mental health, indicates limitations in vitality as well as emotional and social function. During the follow-up, some patients no longer trusted doctors and their families after receiving multiple operations. Moreover, they had physical disability, anorexia, even suicidal thoughts, and some patients lost their job due to this. These findings were similar to those reported by Bhandari et al. and Loannou et al. that orthopedic trauma had substantial impact on perceived mental health and psychosocial function ${ }^{40,41}$. Although the physical health consequences of humeral nonunion and other post-traumatic orthopedic conditions are perhaps more readily observable, the effects of such injuries on mental health may be under-recognized ${ }^{42}$. Therefore, in the regular review of patients with humeral nonunion, the clinician should not only focus on the healing of the fractured callus but also screening and treatment to address psychological health. In this study, approximately $62.90 \%$ of patients had local pain as the chief complaint, so the impact of pain on QoL may be the most important factor in follow-up visit. Successful revision surgery stabilizes the fracture and reduces the patient's sensitivity to fracture pain, so the extent of pain's interference on the QoL of the patient was significantly reduced in the current study.

Interestingly, the humeral nonunion score was found to be lower as compared to the SF-12 scale scores with other long bone nonunion before revision surgery $5,6,42,43$. The possible reasons for this phenomenon 
could be as follows. First, humeral nonunion due to failure of internal fixation often leads to severe appearance deformities or pseudo-articular formation, causing patients to fall into serious psychological obstacles ${ }^{44}$. Second, patients with nonunion of the lower extremities can travel by wheelchair and crutches, but there is no alternative for upper limb nonunion patients to perform some fine motor skills. Finally, in the era of electronic computerization when cell phone and computer use are indispensable (e.g., video games and online shopping), the humeral nonunion made the patient's daily life inconvenient. Therefore, the critical impact on mentality and daily life is a potential contributing factor to their lower scores.

This study had several limitations: (i) This study only examined the final scores and functional outcomes for humeral nonunion, but the situation may be improved at a certain point in time. (ii) The number and geographical region of subjects were restively limited. (iii) Differences in cognition and comprehension of patients could have led to selection bias in final score. (iv) No data on patients with infected humeral nonunion were collected in this study, so the score of patients with humeral nonunion in this study was biased. (v) There is a lack of large population QoL survey in China, therefore we were unable to determine the extent of impact of humeral nonunion on the QoL of normal Chinese people.

\section{Conclusion}

Successful revision surgery of humeral nonunion can greatly improve the subjective feeling and vitality of patients, but it cannot alleviate psychological trauma. Therefore, attention should be paid to the psychological needs of the humeral nonunion patients in rehabilitation treatment.

\section{Abbreviations}

QoL, quality of life; MCS, Mental Component Summary; PCS, Physical Component Summary; BPI-S, brief pain inventory-severity; BPI-I, brief pain inventory- interference; MEPS, Mayo elbow performance score; ROM, range of motion; SF-12, Short Form - 12; FDA, US Food and Drug Administration; BMI, body mass index; GH, general health; PF, physiological function; RP, physiological role; BP, body pain, VT, vitality; SF, social function; $\mathrm{RE}$, emotional role; $\mathrm{MH}$, mental health; $\mathrm{SD}$, standard deviation.

\section{Declarations}

\section{Acknowledgement}

We are thankful for the support of the nursing staffs from the Department of Orthopaedics and Trauma, Hong Hui Hospital and the patients enrolled in this study.

\section{Authors' contributions}

$\mathrm{BZ}$ and $\mathrm{KZ}$ were responsible for the study design, the definition of intellectual content, and for literature research. ZMWQYL and LS analyzed and interpreted data. LLS and HS performed the statistical analysis. 
ZMW $₫ \mathrm{YL}$ and LS drafted the manuscript. TM, CR ZL and QW revised the manuscript. All authors read and approved the final manuscript.

\section{Funding}

This study was supported by Project of Science and Technology Department of Shaanxi Province (No. 2016SF-340, No. 2017ZDXM-SF-009 and No. 2019JQ-976).

\section{Availability of data and material}

The datasets generated and/or analyzed during the current study are not publicly available due to personal reasons, but are available from the corresponding author on reasonable request.

\section{Ethics approval and consent to participate}

Approval was obtained from the Clinical Trials and Biomedical Ethics Committee of Hong Hui Hospital (Approval Number: 201606008), and written informed consent was obtained from all participants.

\section{Consent for publication}

Not applicable.

\section{Competing interests}

The authors declare that they have no competing interests.

\section{Author details}

${ }^{1}$ Department of Orthopaedics and Trauma, Hong Hui Hospital, Xi'an Jiaotong University College of Medicine, Xi'an, Shaanxi,710000, China;

${ }^{2}$ Qinghai University, Xi'ning, Qinghai, 810000, China;

\section{References}

1. Ekholm R, Tidermark J, Tornkvist $\mathrm{H}$, Adami J, Ponzer S. Outcome after closed functional treatment of humeral shaft fractures. J orthop trauma. 2006;20(9):591-6.

2. Peters RM, Claessen FM, Doornberg JN, Kolovich GP, Diercks RL, van den Bekerom MP. Union rate after operative treatment of humeral shaft nonunion-A systematic review. Injury. 2015;46(12):231424.

3. Badman BL, Mighell M, Kalandiak SP, Prasarn M. Proximal humeral nonunions treated with fixedangle locked plating and an intramedullary strut allograft. J orthop trauma. 2009;23(3):173-9.

4. Wichlas F, Tsitsilonis S, Disch AC, et al. Long-term functional outcome and quality of life after successful surgical treatment of tibial nonunions. Int Orthop. 2015;39(3):521-5. 
5. Schottel PC, O'Connor DP, Brinker MR. Time Trade-Off as a Measure of Health-Related Quality of Life: Long Bone Nonunions Have a Devastating Impact. J BoneJoint Surg Am. 2015;97(17):1406-10.

6. Tay WH, de Steiger R, Richardson M, Gruen R, Balogh ZJ. Health outcomes of delayed union and nonunion of femoral and tibial shaft fractures. Injury. 2014;45(10):1653-8.

7. Liu C, Zhang X, Zhang X, Li Z, Xu Y, Liu T. Bone transport with a unilateral external fixator for femoral infected nonunion after intramedullary nailing fixation: A case control study. Med (Baltim). 2019;98(20):e15612.

8. Atalar AC, Kocaoglu M, Demirhan M, Bilsel K, Eralp L. Comparison of three different treatment modalities in the management of humeral shaft nonunions (plates, unilateral, and circular external fixators). J Orthop Trauma. 2008;22(4):248-57.

9. Sun L, Li Z, Ma T, et al. Treatment of atrophic nonunion via autogenous ilium grafting assisted by vertical fixation of double plates: A case series of patients. J Int Med Res. 2019;47(5):1998-2010.

10. Lerner RK, Esterhai JL Jr, Polomano RC, Cheatle MD, Heppenstall RB. Quality of life assessment of patients with posttraumatic fracture nonunion, chronic refractory osteomyelitis, and lower-extremity amputation. Clin Orthop Relat Res. 1993(295):28-36.

11. Luo N, Wang P, Fu AZ, Johnson JA, Coons SJ. Preference-based SF-6D scores derived from the SF-36 and SF-12 have different discriminative power in a population health survey. Med Care. 2012;50(7):627-32.

12. Haverstock BD, Mandracchia VJ. Cigarette smoking and bone healing: implications in foot and ankle surgery. J Foot Ankle Surg. 1998;37(1):69-78.

13. Toro G, Lepore F, Calabro G, et al. Humeral shaft non-union in the elderly: Results with cortical graft plus stem cells. Injury. 2019;50(Suppl 2):75-s79.

14. van de Wall BJM, Ganzert C, Theus $C$, et al. Results of plate fixation for humerus fractures in a large single-center cohort. Arch Orthop Trauma Surg. 2019;10.1007/s00402-019-03319-z.

15. Dailey HL, Wu KA, Wu PS, McQueen MM, Court-Brown CM. Tibial Fracture Nonunion and Time to Healing After Reamed Intramedullary Nailing: Risk Factors Based on a Single-Center Review of 1003 Patients. J Orthop Trauma. 2018;32(7):e263-9.

16. Nauth A, Lee M, Gardner MJ, et al. Principles of Nonunion Management: State of the Art. J Orthop Trauma. 2018;32(Suppl 1):52-s57.

17. Cusick MC, Bonnaig NS, Azar FM, Mauck BM, Smith RA, Throckmorton TW. Accuracy and reliability of the Mayo Elbow Performance Score. J Hand Surg Am. 2014;39(6):1146-50.

18. Lee PH, Wong FK, Wang SL, Chow SK. Substitution of SF-36 by SF-12 Among Hong Kong Chinese Older Adults: Secondary Analysis of Randomized Controlled Trials. Int J Behav Med. 2016;23(5):635-44.

19. Cleeland CS, Nakamura Y, Mendoza TR, Edwards KR, Douglas J, Serlin RC. Dimensions of the impact of cancer pain in a four country sample: new information from multidimensional scaling. Pain. 1996;67(2-3):267-73. 
20. Cleeland CS, Ryan KM. Pain assessment: global use of the Brief Pain Inventory. Ann Acad Med Singap. 1994;23(2):129-38.

21. Chan SF, Ho SM, Poon KW, Ip A, Cheung OY. Pilot assessment of pain of orthopaedic patients in Hong Kong. Psychol Rep. 2005;96(2):527-32.

22. Huang Q, Zhou ZK, Shen B, et al. Validation of the SF-12 among adult Kashin-Beck disease patients in Aba Tibetan autonomous area in China. Rheumatol Int. 2013;33(3):719-24.

23. Wong CK, Lo YY, Wong WH, Fung CS. The associations of body mass index with physical and mental aspects of health-related quality of life in Chinese patients with type 2 diabetes mellitus: results from a cross-sectional survey. Health Qual Life Outcomes. 2013;11:142.

24. Tang WK, Lau CG, Mok V, Ungvari GS, Wong KS. Apathy and health-related quality of life in stroke. Arch Phys Med Rehabil. 2014;95(5):857-61.

25. Si T, Wang G, Yang F, et al. Efficacy and safety of escitalopram in treatment of severe depression in Chinese population. Metab Brain Dis. 2017;32(3):891-901.

26. Lee SW, Lien HC, Chang CS, Ko CW, Tung CF, Yeh HZ. Health-related quality of life of subjects with Barrett's esophagus in a Chinese population. PloS one. 2017;12(12):e0190201.

27. Wang Y, Fan S, Wang H, Li L, Jia Y, Chai L. Pictorial Representation of Illness and Self MeasureRevised 2 (PRISM-R2): an effective tool to assess perceived burden of thyroid cancer in mainland China. Support Care Cancer. 2018;26(9):3267-75.

28. Li Q, Xu Y, Zhou H, Loke AY. Factors influencing the health-related quality of life of Chinese advanced cancer patients and their spousal caregivers: a cross-sectional study. BMC Palliat Care. 2016;15:72.

29. Choi EP, Wong CK, Wan EY, et al. The internal and external responsiveness of Functional Assessment of Cancer Therapy-Prostate (FACT-P) and Short Form-12 Health Survey version 2 (SF-12 v2) in patients with prostate cancer. Qual Life Res. 2016;25(9):2379-93.

30. Yao XI, Ni MY, Cheung F, et al. Change in moderate alcohol consumption and quality of life: evidence from 2 population-based cohorts. CMAJ. 2019;191(27):E753-60.

31. Wan EYF, Yu EYT, Chin WY, Choi EPH, Wu T, Lam CLK. Evaluation of the responsiveness of Short Form-12 Health Survey version 2 (SF-12v2) in Chinese patients with hypertension in primary care. Qual Life Res. 2019;28(10):2851-7.

32. Hu Z, Man GCW, Kwok AKL, et al. Global sagittal alignment in elderly patients with osteoporosis and its relationship with severity of vertebral fracture and quality of life. Arch Osteoporos. 2018;13(1):95.

33. Wong CKH, Chen JY, Fung SKS, et al. Health-related quality of life and health utility of Chinese patients undergoing nocturnal home haemodialysis in comparison with other modes of dialysis. Nephrology (Carlton). 2019;24(6):630-7.

34. Gao B, Yang S, Liu X, Ren X, Liu D, Li N. Association between social capital and quality of life among urban residents in less developed cities of western China: A cross-sectional study. Medicine (Baltimore). 2018;97(4):e9656. 
35. Guo VY, Yu EYT, Wong RSM, et al. Maternal mental quality of life mediates the associations between intimate partner abuse against mothers and their children's behaviours and quality of life in lowincome Chinese families. Qual Life Res. 2017;26(12):3297-306.

36. Choi EP, Lam CL, Chin WY. Mental Health Mediating the Relationship Between Symptom Severity and Health-Related Quality of Life in Patients with Lower Urinary Tract Symptoms. Low Urin Tract Symptoms. 2016;8(3):141-9.

37. Xiang YT, Wong TS, Tsoh J, et al. Quality of life in older patients with chronic obstructive pulmonary disease (COPD) in Hong Kong: a case-control study. Perspect Psychiatr Care. 2015;51(2):121-7.

38. Brinker MR, Trivedi A, O'Connor DP. Debilitating Effects of Femoral Nonunion on Health-Related Quality of Life. J Orthop Trauma. 2017;31(2):e37-42.

39. Wang XS, Mendoza TR, Gao SZ, Cleeland CS. The Chinese version of the Brief Pain Inventory (BPI-C): its development and use in a study of cancer pain. Pain. 1996;67(2-3):407-16.

40. Bhandari M, Busse JW, Hanson BP, Leece P, Ayeni OR, Schemitsch EH. Psychological distress and quality of life after orthopedic trauma: an observational study. Can J Surg. 2008;51(1):15-22.

41. Ioannou LJ, Cameron PA, Gibson SJ, et al. Traumatic injury and perceived injustice: Fault attributions matter in a "no-fault" compensation state. PloS one. 2017;12(6):e0178894.

42. Brinker MR, Hanus BD, Sen M, O'Connor DP. The devastating effects of tibial nonunion on healthrelated quality of life. J Bone Joint Surg Am. 2013;95(24):2170-6.

43. Peng Y, Ji X, Zhang L, Tang P. Double locking plate fixation for femoral shaft nonunion. Eur J Orthop Surg Traumatol. 2016;26(5):501-7.

44. Johnson L, Igoe E, Kleftouris G, Papachristos IV, Papakostidis C, Giannoudis PV. Physical Health and Psychological Outcomes in Adult Patients with Long-bone Fracture Non-unions: Evidence Today. J Clin Med. 2019;8(11):1998.

\section{Figures}




\section{SF-12 Physical Component Summary (PCS)Scores}

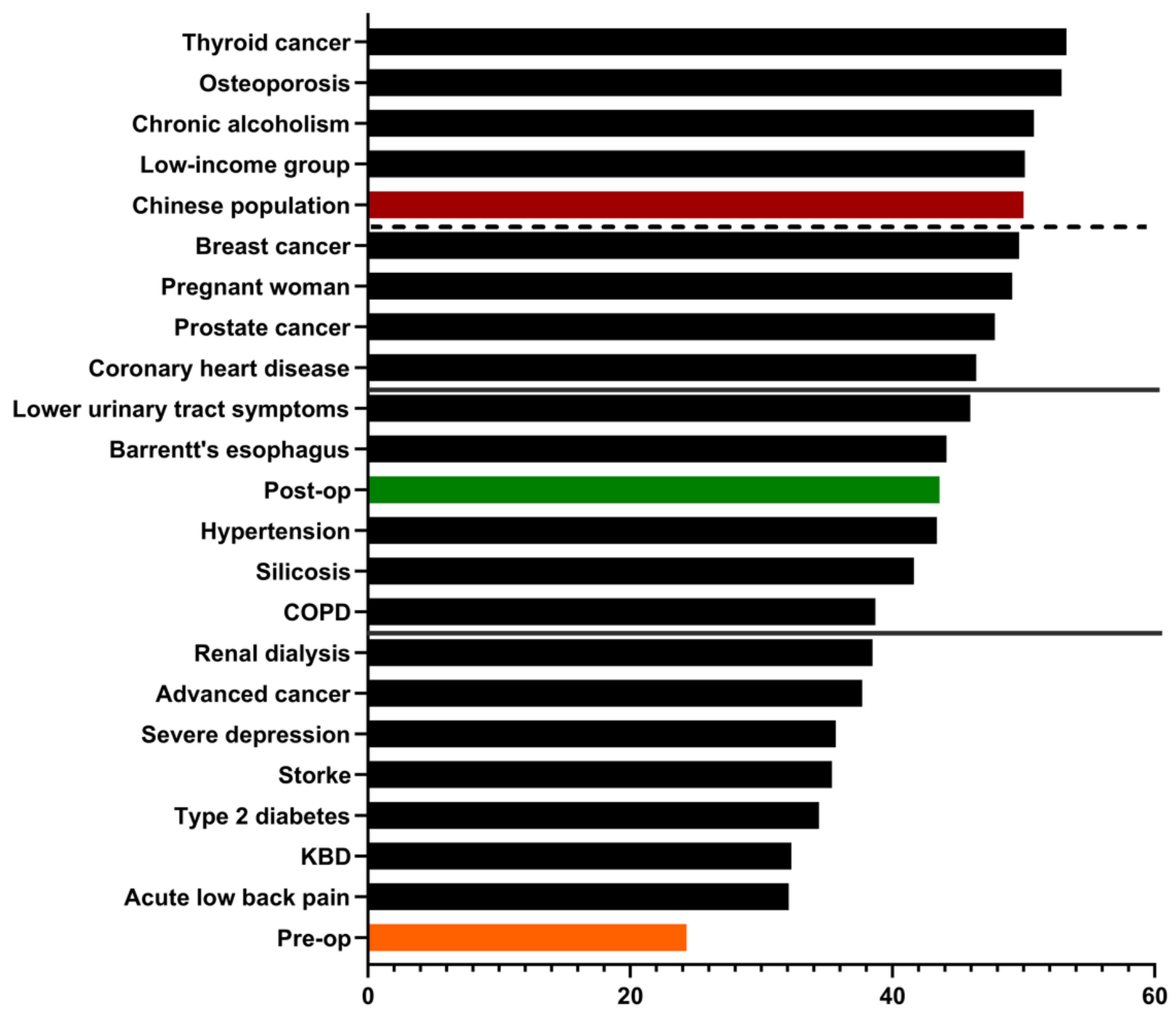

Figure 1

Mean SF-12 PCS scores according to diagnosis. Abbreviations: KBD, Kashin-Beck disease; COPD, Chronic Obstructive Pulmonary Disease."Post-op" means that the fracture ends were healed smoothly. The medical conditions below the dashed line were associated with significantly $(p<0.05)$ better physical health compared with pro-op.Compared with post-op PCS, the medical condition above theupper solid line or below the lower solid line were associated with significantly $(p<0.05)$ better or worse physical health, respectively. 


\section{SF-12 Mental Component Summary (MCS)Scores}

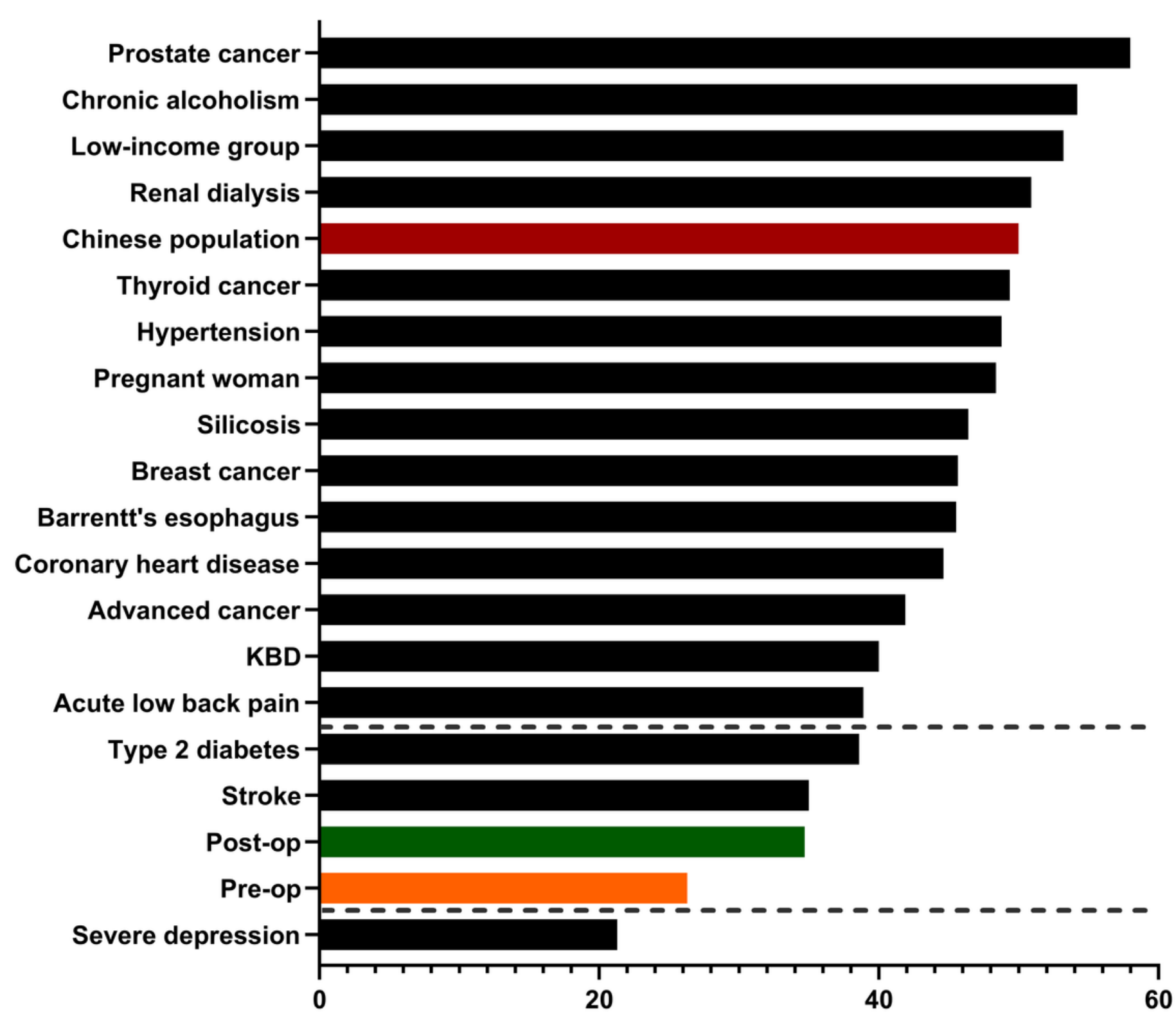

Figure 2

Mean SF-12 MCS scores according to diagnosis. Abbreviations: KBD, Kashin-Beck disease; COPD, Chronic Obstructive Pulmonary Disease."Post-op" means that the fracture ends were healed smoothly. The medical condition above theupper dashed line or below the lower dashed line were associated with significantly $(p<0.05)$ better or worse mental health, respectively,compared with pro-op and post-op MCS. 